\title{
Erratum to: Role of transcription regulatory sequence in regulation of gene expression and replication of porcine reproductive and respiratory syndrome virus
}

\author{
Chengbao Wang ${ }^{1,2}$, Han Meng ${ }^{1}$, Yujin Gao ${ }^{1}$, Hui Gao ${ }^{1}$, Kangkang Guo ${ }^{1}$, Fernando Almazan ${ }^{3}$, Isabel Sola ${ }^{3}$,
} Luis Enjuanes ${ }^{3}$, Yanming Zhang ${ }^{1 *}$ and Levon Abrahamyan ${ }^{2,4^{*}}$ (])

\section{Erratum to: Vet Res (2017) 48:41 DOI 10.1186/s13567-017-0445-2}

After publication of the article [1], it has been brought to our attention that an acknowledgement has been omitted from the original article. The authors would like to include the following, The authors also thank Prof. EnMin Zhou (Northwest A\&F University) and his laboratory for technical support."

\section{Author details}

${ }^{1}$ Department of Preventive Veterinary Medicine, College of Veterinary Medicine, Northwest A\&F University, No. 22 Xinong Road, Yangling, Shaanxi 712100, China. ${ }^{2}$ Swine and Poultry Infectious Diseases Research Center (CRIPA) and Research Group on Infectious Diseases in Production Animals (GREMIP), Faculty of Veterinary Medicine, Université de Montréal, 3200 Sicotte, Saint-Hyacinthe, QC J2S 2M2, Canada. ${ }^{3}$ Department of Molecular and Cell Biology, Spanish National Centre for Biotechnology, CNB-CSIC, C/Darwin No. 3, Campus Universidad Autonoma. Cantoblanco, 28049 Madrid, Spain. ${ }^{4}$ Faculty of Veterinary Medicine, Department of Pathology and Microbiology, Université de Montréal, 3200 Sicotte, Saint-Hyacinthe, QC J2S 2M2, Canada.

\section{Publisher's Note \\ Springer Nature remains neutral with regard to jurisdictional claims in pub- lished maps and institutional affiliations.}

Received: 13 September 2017 Accepted: 13 September 2017

Published online: 20 September 2017

\section{Reference}

1. Wang C, Meng H, Gao Y, Gao H, Guo K, Almazan F, Sola I, Enjuanes L, Zhang Y, Abrahamyan L (2017) Role of transcription regulatory sequence in regulation of gene expression and replication of porcine reproductive and respiratory syndrome virus. Vet Res. 48:41. doi:10.1186/ s13567-017-0445-2

\footnotetext{
*Correspondence: zhangym@nwsuaf.edu.cn; levon.abrahamyan@umontreal.ca

${ }^{1}$ Department of Preventive Veterinary Medicine, College of Veterinary

Medicine, Northwest A\&F University, No. 22 Xinong Road, Yangling, Shaanxi 712100, China

${ }^{4}$ Faculty of Veterinary Medicine, Department of Pathology and Microbiology, Université de Montréal, 3200 Sicotte, Saint-Hyacinthe, QC J2S 2M2, Canada

Full list of author information is available at the end of the article
} provided you give appropriate credit to the original author(s) and the source, provide a link to the Creative Commons license, and indicate if changes were made. The Creative Commons Public Domain Dedication waiver (http://creativecommons.org/ publicdomain/zero/1.0/) applies to the data made available in this article, unless otherwise stated. 